\title{
BMJ Open Drowning among fishing communities on the Tanzanian shore of lake Victoria: a mixed-methods study to examine incidence, risk factors and socioeconomic impact
}

Hilary S Whitworth (10 ,1,2 Joyce Pando, ${ }^{1}$ Christian Hansen, ${ }^{3,4}$ Natasha Howard, ${ }^{5}$ Amen Moshi, ${ }^{1}$ Otto Rocky, ${ }^{1}$ Happiness Mahanga, ${ }^{1}$ Mtoro Jabbar, ${ }^{1}$ Philip Ayieko, ${ }^{1,4}$ Saidi Kapiga, ${ }^{1,4}$ Heiner Grosskurth, ${ }^{1,4}$ Deborah Watson-Jones ${ }^{1,2}$

To cite: Whitworth HS, Pando J, Hansen C, et al. Drowning among fishing communities on the Tanzanian shore of lake Victoria: a mixed-methods study to examine incidence, risk factors and socioeconomic impact. BMJ Open 2019;9:e032428. doi:10.1136/ bmjopen-2019-032428

- Prepublication history and additional material for this paper are available online. To view these files, please visit the journal online (http://dx.doi org/10.1136/bmjopen-2019032428).

Received 18 June 2019 Revised 22 September 2019 Accepted 05 November 2019

Check for updates

(C) Author(s) (or their employer(s)) 2019. Re-use permitted under CC BY-NC. No commercial re-use. See rights and permissions. Published by BMJ.

For numbered affiliations see end of article.

Correspondence to Dr Hilary S Whitworth; hilary.whitworth@|shtm.ac.uk

\section{ABSTRACT}

Objectives To estimate the incidence of unintentional fatal drowning and describe associated risk factors among Lake Victoria fishing communities, and to assess perceived social, financial and other impacts among families and colleagues of persons who drowned.

Design A retrospective, observational mixed-methods study, conducted between September 2017 and February 2018.

Setting Eight Tanzanian fishing communities on Lake Victoria.

Participants Persons who drowned in the preceding 24 months were identified using an extensive community networking approach. Adult family members, colleagues or community members familiar with the habits and behaviours of people who drowned and/or circumstances of drowning incidents participated in surveys $(n=44)$ and in-depth interviews $(n=22)$

Main outcome measures Pooled drowning incidence, with sensitivity analyses allowing for uncertainties in population estimates. Risk factors were identified through the evaluation of behavioural characteristics of persons who drowned and circumstances of drowning incidents. Perceived socioeconomic impacts were assessed through semi-structured interviews with their family members and colleagues.

Results The estimated drowning incidence was 217/100 000 person-years $(95 \% \mathrm{Cl} 118$ to $425 / 100000)$. Of 86 victims identified, $70(81 \%)$ were fishermen $(79 \%$ aged 18-40 years; all men) and 9 were children (all $\leq 10$ years). All deaths occurred in the lake. Most adults (65/77; 84\%) were fishing from a boat when they drowned; $57 / 77(74 \%)$ died in the evening (from $\sim 5 \mathrm{pm}$ ) or at night. Six children $(67 \%)$ drowned while swimming/playing at the lakeshore unsupervised. Few victims (2/86; 2\%) were wearing a life jacket at the time of death. Reported socioeconomic impacts of these deaths ranged from income loss to family break-up.

Conclusions Drowning is a significant risk in Tanzanian lakeside fishing communities, with estimated mortality exceeding national incidence rates of fatal malaria, tuberculosis or HIV, but preventative strategies appear
Strengths and limitations of this study

- An extensive networking approach was implemented at each of the eight included fishing communities to identify most or all deaths due to drowning within the preceding 24 months, and a careful comparison of each victim and incident was conducted to enable exclusion of duplicate accounts.

- However, a lack of available comprehensive death records means that under-reporting of deaths cannot be ruled out.

- Incidence estimations used census data with 3\% annual population growth applied as the populationat-risk, whereas sensitivity analyses used community-derived population estimates.

- A limitation of this study is that the cause of death was rarely confirmed by a post-mortem, as is typical of this setting where the deceased are seldom taken to hospitals, and facilities enabling post-mortem are limited.

- Our qualitative data on the perceived impacts of drowning represent an interesting preliminary assessment, but the migration of family members and colleagues of persons who drowned subsequent to drowning events meant that data were limited.

uncommon. Socioeconomic impact at the family level may be substantial. Intervention strategies are required to reduce the drowning burden among this neglected at-risk population.

\section{INTRODUCTION}

The WHO recently highlighted drowning as a major but neglected public health threat worldwide, killing approximately 320000 people annually. ${ }^{1}$ Data on drowning from Africa are limited and mostly from South Africa. $^{2-4}$ Of the few non-South African studies contributing drowning data over the past 30 years, ${ }^{5-10}$ most were not specifically 
designed to evaluate drowning but examined causes of injury or death more generally. ${ }^{5-9}$ Nonetheless, WHO estimates that the African region may bear the highest drowning death rates globally. ${ }^{11}$ A recent systematic review estimated that the average incidence of fatal drowning across Tanzania is 5.1/100 000 person-years but the incidence was highly variable across regions, reaching up to $16.7 / 100000$ person-years in the Geita region adjoining Lake Victoria. ${ }^{8}$

Worldwide, drowning mostly affects young people and children, particularly those aged 1-4 years. ${ }^{245811}$ However, fishermen who spend significant time on large water bodies are likely to be a high-risk group, particularly in low and middle-income countries (LMICs) where boating and life-saving infrastructure may be sub-standard, and safe boating practices insufficiently enforced. Risk factors for drowning in LMICs include male gender, ${ }^{28}$ rural environment and limited swimming ability, ${ }^{2}$ all of which are likely to be common factors among people from fishing communities in these regions. A population-based study in rural Malawi found that fishermen had higher odds of drowning than farmers. ${ }^{5}$ Furthermore, odds of drowning were higher among children from fishing compared with farming households.

Lake Victoria, Africa's largest lake, has many lakeside communities. The fishing industry is estimated to support the livelihoods of over three million people around the lake. ${ }^{12}$ However, the weather and water conditions on Lake Victoria are notoriously changeable and can be extreme. ${ }^{13}$ A recent observational study conducted at boat landing communities on the Ugandan lakeshore reported an estimated drowning fatality rate of 502/100 000 person-years. ${ }^{10}$ Fishermen are often the bread-winners of typically large families. Thus, the socioeconomic impact of drowning among fishermen may be considerable.

Here we report on a study conducted to estimate the incidence of deaths due to drowning in Tanzanian fishing communities on Lake Victoria, to describe risk factors among persons who drowned and to assess the perceived socioeconomic impact of drowning deaths in these communities.

\section{METHODS}

We conducted a retrospective observational study, applying both quantitative and qualitative research methods, between September 2017 and February 2018. The study was approved by the London School of Hygiene and Tropical Medicine Observational Research Ethics Committee (ref.MR/53/100/480) and Tanzanian Medical Research Coordinating Committee National Institute for Health Research Ethics Committee (ref.14184) and was funded by the Royal National Lifeboat Institution.

Our study was conducted in five island and three mainland fishing communities around the Tanzanian shoreline of Lake Victoria (figure 1). Of the estimated three million people living in Lake Victoria fishing communities, ${ }^{12}$ approximately $60 \%$ are thought to reside within Tanzania. The fishing industry provides a major source of income for these communities, with men filling roles as boat builders, boat owners, crew and in fisheries management, and women processing and trading fish. Lake Victoria fishing communities are typically poor and have high rates of illiteracy. ${ }^{14}$ Many have limited availability of services such as schools (particularly post primary education) and health facilities. Housing largely comprises temporary or semi-permanent structures, and often has no electricity supply; frequently, the lake is a household's main source of water. Land-based transport is typically on dirt roads, often by bicycle or motorbike; most community members do not own cars. Many lakeside fishing communities have a high prevalence of HIV/AIDS, ${ }^{14}$ and other common health threats include malaria, bilharzia, tuberculosis, syphilis, typhoid and cholera.

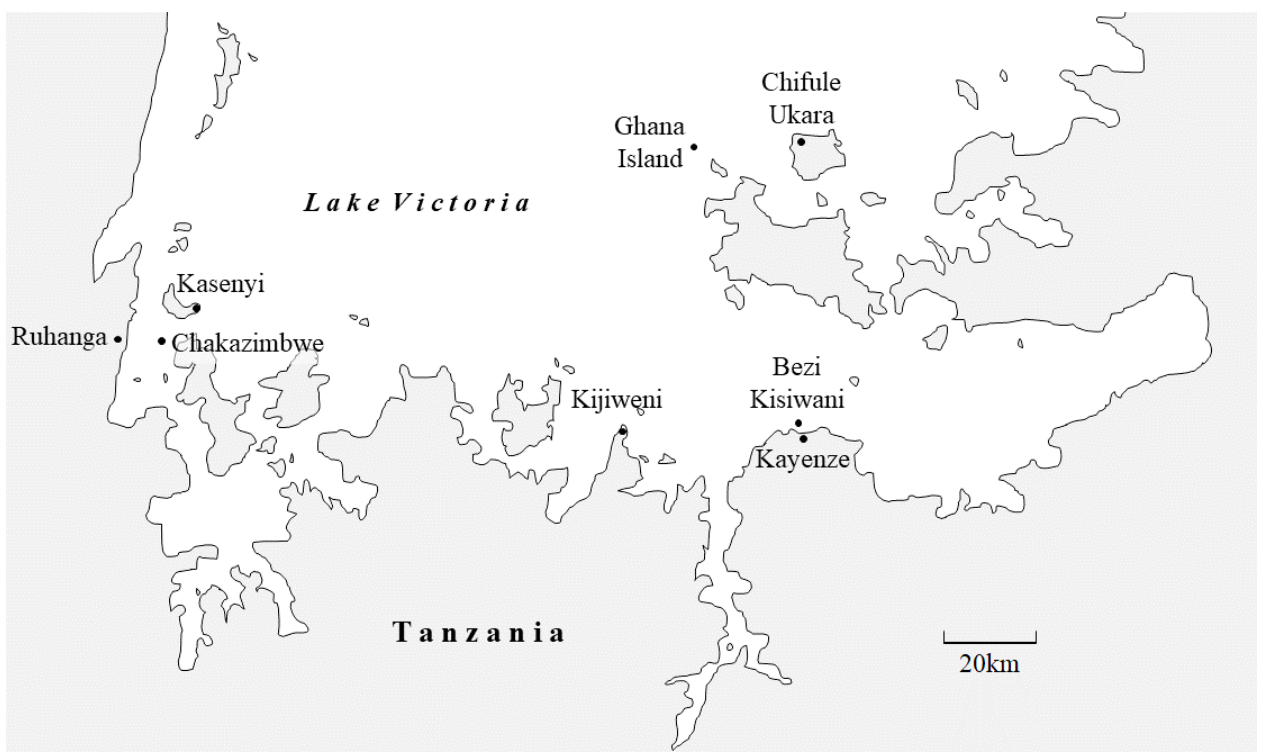

Figure 1 Map of study sites. Five island and three mainland communities were included in the study. 


\section{Data collection}

To be included in our study, fishing communities had to be permanent (not temporary) settlements, have a population size of $\geq 1000$, and have a Beach Management Unit (BMU; a local-level fisheries management group that typically keeps registers of fishermen). Data were collected by five Tanzanian researchers experienced in quantitative and qualitative methodologies. We developed, assessed and optimised data collection tools in an earlier pilot study. ${ }^{15}$

\section{Identification of drowning deaths}

We used an extensive networking approach at the level of both the local authorities and the community to attempt to identify all drowning deaths occurring within each community over the preceding 24 months. Specific details on how deaths were identified are provided in the online supplementary material. We took steps to ensure that only deaths occurring in the selected recall period were included. First, the 24-month recall period was selected to include only recent deaths, reducing the risk of recall bias. Second, we sought to include participants who most knew the persons who drowned and the circumstances of their deaths. Third, the study staff validated timing by encouraging the participant to relate the time of the incident to other key/landmark events or seasons. Reports of persons who drowned who were not permanently or temporarily resident in the local community were excluded

For all reports of a death, we captured basic descriptive data about the victim and death in face-to-face interviews using structured, anonymised questionnaires. These data were used to generate a catalogue of all drowning reports, and to confirm that the most likely cause of each death was drowning (through assessment of the events leading to the death, taking into consideration other relevant factors such as post-mortem assessment by health professionals where available). The specific details of the persons who drowned (name, place of residence, gender, age or age group) and circumstances of the drowning event were compared to allow the exclusion of any duplicated reports of drowning deaths.

Data collection continued until saturation (ie, no new deaths were identified). A final list of drowning deaths was created and numbers of cases occurring within the past 24 months were compiled for each community. Acknowledging the possibility that some drowning deaths were not identified due to a lack of comprehensive death records, our strategy allowed us to estimate the minimum likely incidence of fatal drowning in these communities.

\section{Estimation of population size}

We aimed to obtain population size estimates for 2016 , the approximate midpoint of the 2-year recall period for recorded drowning deaths. We first obtained population size estimates from the most recent (2012) Tanzanian census for each of the study communities and applied an annual population growth factor of $3 \%$ for 4 years to obtain 2016 population size estimates. The 3\% growth factor was based on published regional and national population growth figures since 2002. ${ }^{16-18}$ This method produced our 'census-derived 2016 population estimates'. We also requested data from local authorities at each community on locally held population numbers for 2016 (for our 'community-derived 2016 estimates').

\section{Description of risk factors for drowning}

To obtain a detailed account of each drowning victim on the above list, we identified a family member, friend, colleague or other community member (aged $\geq 18$ years) who knew the deceased and circumstances of the incident. Specific details on the identification and recruitment of these participants are provided in the online supplementary material. After written informed consent, we collected data on demographics and characteristics of the persons who drowned and the circumstances surrounding their deaths in face-to-face interviews using pre-tested, structured, anonymised questionnaires.

\section{Assessing the socioeconomic impact of drowning deaths}

We conducted semi-structured interviews with 22 family members, colleagues and friends of persons who drowned (aged $\geq 18$ years) to evaluate perceived socioeconomic impacts of the deaths. Interview participants were selected by study staff using a prioritisation system (described in the online supplementary material) to include persons who truly knew and understood the impact of the deaths. After written informed consent, participants were asked whether and how the death had affected them personally, the victim's family, household economics and (where applicable) his/her business (online supplementary box 1). Interviews were conducted in Swahili using pre-tested question guides. All interviews were anonymously audio-recorded, transcribed and translated to English.

\section{Patient and public involvement}

Participants of the pilot study ${ }^{15}$ described previously were invited to provide feedback to study staff on the data collection aspects (semi-structured interviews and questionnaires) of the study. This feedback was considered when finalising data collection tools and methods for the main study. Additionally, preliminary meetings were conducted with community and BMU leaders at each site to seek advice on appropriate approaches to conducting community meetings, recruiting participants and performing data collection in their community, taking into account local cultures, beliefs, practices and sensitivities. Community and BMU leaders played a key role in facilitating the research at each site by organising and attending community meetings and promoting the study in their community. After study completion, community and BMU leaders facilitated community meetings for dissemination of study results by staff to community members. 


\section{Analyses}

Quantitative questionnaires on persons who drowned and risk factors were pre-programmed into electronic handheld tablets using Open Data Kit software, and data were downloaded to STATA (V.15) for analysis. Personyears-at-risk (PYAR) were calculated by multiplying the estimated population size by the 2-year recall period, and incidence estimations (expressed as the death rate per 100000 PYAR) were calculated using the total number of deaths identified in the preceding 24 months divided by the total PYAR. Incidence estimations specifically among fishermen were calculated assuming that this sub-group accounts for one eighth of the total population (based on an approximate 1:1 male-to-female ratio, half the population being aged $>17$ years, ${ }^{16} 17$ and half adult males being fishermen (observations from rural fishing communities)). In primary analyses, the population at-risk was determined using census-derived 2016 population size estimates. To account for potential margins of error in the census-derived estimates, we performed sensitivity analyses of incidence rates using community-derived 2016 population size estimates. For both primary and sensitivity analyses, $95 \%$ CIs for the overall incidence rate were derived using the 2.5 and 97.5 percentiles of the empirical bootstrap distribution. Descriptive tables were generated for all other quantitative data.

Qualitative interview data on socioeconomic impacts were analysed thematically using deductive and inductive coding as described by Clarke and Braun, ${ }^{19}$ including steps for data familiarisation, generation of initial codes and identification and definition of themes.

\section{RESULTS}

\section{Estimated incidence of fatal drowning}

We identified 86 drowning deaths (70 among fishermen) occurring within the preceding 24 months in an estimated population of 19775 persons (based on censusderived 2016 data) across the eight communities (table 1 and figure 2). The resulting pooled drowning incidence across all eight study communities was 217/100 000 person-years (95\% CI 118 to 425). Among fishermen, the estimated incidence of drowning (assuming a population size of 2,472) was 1416/100 000 person-years (95\% CI 694 to 2949; equivalent to about $1.4 \%$ ). Using the communityderived 2016 population estimates, giving a total population of 21,521, the pooled drowning incidence across the eight communities was 200/100 000 person-years (95\% CI 115 to 311), and the incidence among fishermen (assuming $\mathrm{n}=2690)$ was $1301 / 100000$ person-years $(95 \%$ CI 671 to 2173).

\section{Demographics of risk factor questionnaire participants}

Forty-four respondents completed detailed questionnaires on the demographics, characteristics and drowning circumstances of the 86 identified victims (figure 2). Interviewees were aged 21-65 years (median 40 years) and mostly men $(35 / 44 ; 79.5 \%)$. Respondents included victims' family members $(15 / 86 ; 17 \%)$, colleagues $(8 / 86$;

Table 1 Number and estimated incidence of drowning deaths over a 2 year recall period from eight Tanzanian lakeside communities

\begin{tabular}{|c|c|c|c|c|c|c|c|}
\hline & $\begin{array}{l}\text { Total } \\
\text { drowning } \\
\text { deaths }\end{array}$ & $\begin{array}{l}\text { Deaths } \\
\text { among } \\
\text { fishermen }\end{array}$ & $\begin{array}{l}\text { Deaths } \\
\text { among } \\
\text { children } \\
(\leq 16 \mathrm{y}) \\
\end{array}$ & $\begin{array}{l}2012 \text { census } \\
\text { population } \\
\text { estimate }\end{array}$ & $\begin{array}{l}\text { Census- } \\
\text { derived } 2016 \\
\text { population } \\
\text { estimate* } \dagger\end{array}$ & $\begin{array}{l}\text { Person- } \\
\text { time at risk } \\
\text { (years)‡ }\end{array}$ & $\begin{array}{l}\text { Incidence } \\
\text { per } 100000 \\
\text { person-years }\end{array}$ \\
\hline \multicolumn{8}{|c|}{ Island communities } \\
\hline Ghana & 13 & $10(77 \%)$ & $1(8 \%)$ & 3000 & 3377 & 6753 & 192 \\
\hline Kasenyi & 11 & $9(82 \%)$ & $1(9 \%)$ & 4436 & 4993 & 9986 & 110 \\
\hline Chakazimbwe & 6 & $5(83 \%)$ & $1(17 \%)$ & 1500 & 1688 & 3377 & 178 \\
\hline Bezi Kisiwani & 2 & $2(100 \%)$ & $0(0 \%)$ & 1889 & 2126 & 4252 & 47 \\
\hline Chifule Ukara & 11 & $8(73 \%)$ & $2(18 \%)$ & 1253 & 1410 & 2821 & 390 \\
\hline \multicolumn{8}{|c|}{ Mainland communities } \\
\hline Kijiweni & 28 & $26(93 \%)$ & $1(4 \%)$ & 992 & 1117 & 2233 & 1253 \\
\hline Kayenze & 5 & $2(40 \%)$ & $1(20 \%)$ & 2800 & 3151 & 6303 & 79 \\
\hline Ruhanga & 10 & $8(80 \%)$ & $2(20 \%)$ & 1700 & 1913 & 3827 & 261 \\
\hline \multicolumn{8}{|l|}{ All communities } \\
\hline Overall & 86 & 70 (81\%) & $9(10 \%)$ & 17570 & 19775 & 39550 & 217 \\
\hline
\end{tabular}

*Assuming 3\% annual population growth between 2012 and 2016.

†Community-derived 2016 population estimates were as follows: Ghana = 3500; Kasenyi = 3225; Chakazimbwe = 2000; Bezi Kisiwani = 2600; Chifule Ukara = 2000; Kijiweni $=2645$; Kayenze $=3551$; Ruhanga $=2000 ;$ Total $=21521$.

$\ddagger$ Calculated as the 2012 census population estimate with a $3 \%$ population growth factor applied for 4 years (to 2016), multiplied by the 2year recall period, and rounded to the nearest whole number. 


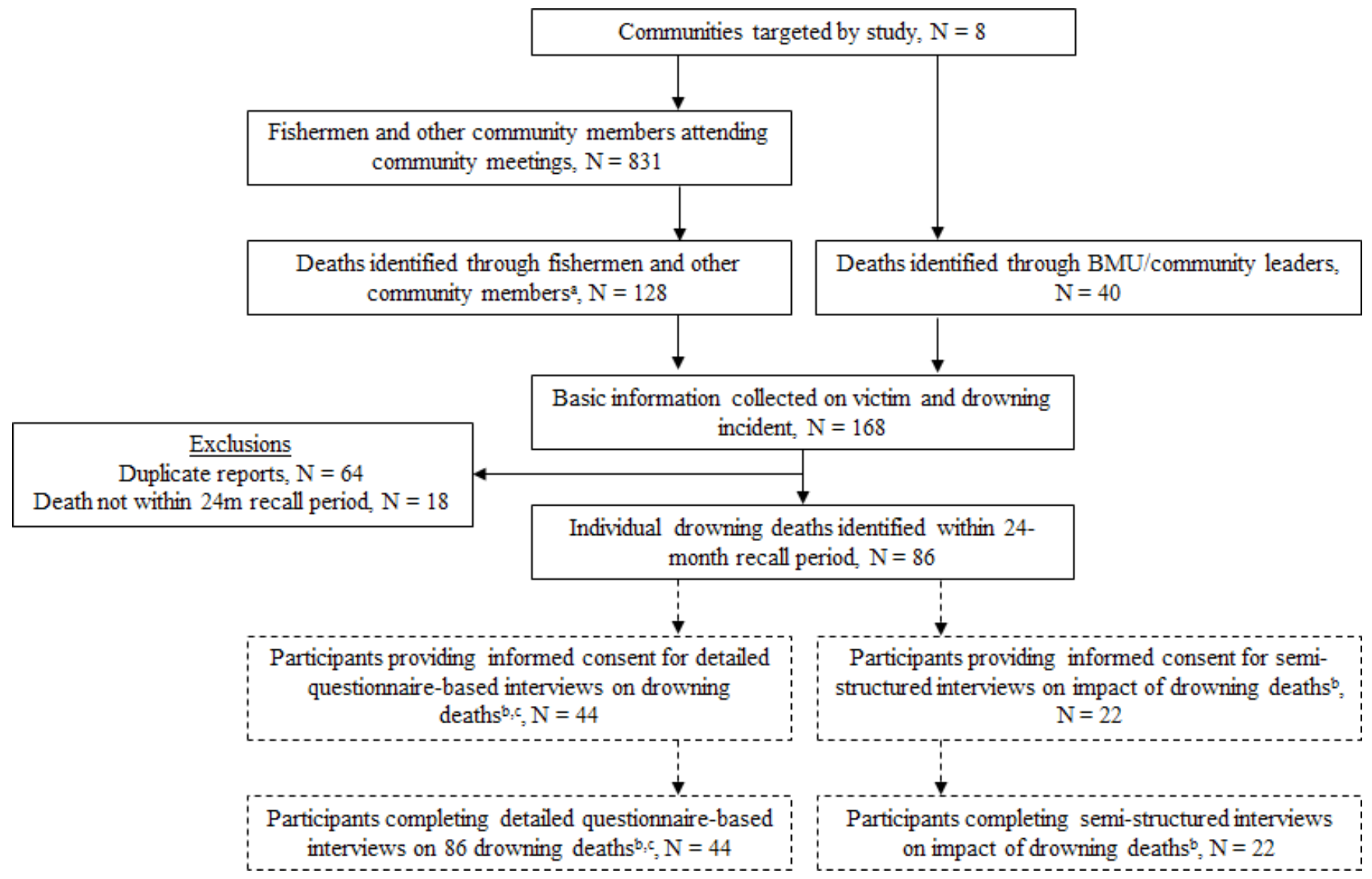

Figure 2 Study flow chart. Boxes and arrows with solid lines show steps taken to determine numbers of drowning deaths (which were used for incidence estimations). Those with dotted lines show subsequent detailed questionnaire-based interviews and semi-structured interviews with family members, colleagues and other community members. ${ }^{a}$ Deaths identified through fishermen and other community members were captured through surveys with those attending community meetings $(n=600)$ and Snowball sampling. ${ }^{b}$ In some cases, the participants who completed the detailed questionnaire-based interviews and/or the semi-structured interviews were the same people who reported the death initially. In other cases, we obtained referrals to suitable participants from BMU or community leaders or other community members. ${ }^{\circ}$ For all persons who drowned, we were able to identify and enrol a study participant who could provide most or all information required in the detailed questionnairebased interview. Some participants provided data on more than one victim. BMU, Beach Management Unit.

$9 \%)$, community leaders $(16 / 86 ; 19 \%)$ and friends or other members of the same community $(47 / 86 ; 55 \%)$.

\section{Demographics and characteristics of persons deceased due to drowning}

Of the 86 persons who drowned, 77 (90\%) were adults, of whom $70(91 \%)$ were fishermen (online supplementary table 1). All deceased fishermen were men, $55(79 \%)$ died aged $18-40$ years and $39(56 \%)$ were married. Of seven other adult community members who drowned, five $(71 \%)$ were men, five aged $18-40$ years and five married. All nine deceased children were $\leq 10$ years and six $(67 \%)$ were girls.

Routine fishing practices among the 70 deceased fishermen while they were still alive are shown in table 2 . Among the seven other adult victims, the most common reasons for going in or near the lake were to buy or sell fish $(6 / 7)$, for travel $(4 / 7)$ or to collect water $(4 / 7)$. Five $(71 \%)$ could not swim, yet none were reported to own or ever use a life jacket. Most (5/9) of the children who drowned did not routinely go in or near water, but three went in or near the lake regularly for recreation. One child could swim; none were reported to ever wear a life jacket.

\section{Circumstances of drowning deaths}

All 86 victims drowned in the lake (online supplementary box 2). Of the 77 adult victims, 71 (92\%) were in a boat prior to the incident, $65(92 \%)$ of whom were fishing at the time. Of these, 49 of $71(69 \%)$ drowned because the boat sank or capsized in bad weather. Of the nine child victims, only one was in a boat prior to the incident; six (67\%) drowned while swimming or playing at the lakeshore. One of the nine had sought permission to go in or near the water, and two were supervised by an adult. There were no barriers preventing children from entering the lake.

Of all 86 drowning deaths, 63 (73\%) occurred at night and $42(49 \%)$ during bad weather with rough water conditions. Two victims were wearing life jackets at the time of death (both adults), but the life jacket did not prevent them from drowning. Twelve (16\%) adults were 
Table 2 Routine fishing and boating practices of deceased fishermen while still alive

\begin{tabular}{lc} 
Variable & $\begin{array}{l}\text { Fishermen } \\
(\mathbf{n}=70)\end{array}$ \\
\hline Time worked in fishing industry & \\
Do not know & $2(3)$ \\
$<1$ year & $7(10)$ \\
1-10 years & $47(67)$ \\
$>10$ years & $14(20)$ \\
Routinely fished at night & \\
Yes & $58(83)$ \\
No & $12(17)$ \\
Able to swim* & \\
Yes & $22(31)$ \\
No & $43(61)$ \\
Do not know & $5(7)$ \\
Ever used a lifejacket when fishing & \\
Yes & $4(5)$ \\
No & $66(94)$
\end{tabular}

Ever used other type(s) of buoyancy device when fishing

\begin{tabular}{lc} 
Yes $†$ & $6(9)$ \\
No/Do not know & $64(92)$ \\
Used to go fishing in bad weather & \\
Yes & $31(44)$ \\
No/Do not know & $39(55)$ \\
Ever drank alcohol or used drugs while fishing & \\
Yesł & $17(24)$ \\
No/Do not know & $53(76)$ \\
Method(s) of power of fishing boat most commonly used§ \\
Engine & $27(40)$ \\
Sails, alone or with paddles & $4(5)$ \\
Paddles only & $36(54)$ \\
Ever fished from a poorly maintained fishing boat§ \\
Yes & $25(37)$ \\
No/Do not know & $42(62)$ \\
\hline
\end{tabular}

Data shown are $\mathrm{N}(\%)$.

*Swimming ability of the person who drowned, as reported by the family member, colleague or community member who completed the questionnaire on their behalf.

†In all cases, the other type of buoyancy device reported was a large plastic container (such as an empty plastic fuel or water container).

†In all cases where drug use was reported, the drug taken was marijuana (khat).

$\S$ Data are shown for 67 fishermen who fished from boats. All of these reportedly fished from boats made from wood. Boat overloading was rarely reported $(4 / 67 ; 5 \%)$. Three fishermen fished only from the shore.

reportedly under the influence of alcohol when they drowned; 4 of 77 (5\%) had reportedly taken illegal drugs (marijuana in all cases). Of 72 adult and child victims on boats prior to drowning, 57 (79\%) were on small (typically
Table 3 Circumstances of drowning deaths among fishermen

\begin{tabular}{|c|c|}
\hline Variable & $\begin{array}{l}\text { Fishermen } \\
(\mathrm{N}=70)\end{array}$ \\
\hline \multicolumn{2}{|l|}{ Time of drowning incident } \\
\hline Morning/afternoon & $18(25)$ \\
\hline Evening/night & $52(74)$ \\
\hline \multicolumn{2}{|l|}{ Weather conditions } \\
\hline Strong winds, heavy rain & $39(56)$ \\
\hline Moderate winds, light rain & $17(24)$ \\
\hline $\begin{array}{l}\text { Little or no wind, no rain/Do not } \\
\text { know }\end{array}$ & $14(20)$ \\
\hline \multicolumn{2}{|l|}{ Water conditions } \\
\hline Rough & $40(57)$ \\
\hline Moderate & $11(16)$ \\
\hline Slight/Calm/Do not know & $19(27)$ \\
\hline \multicolumn{2}{|l|}{ Victim was wearing a lifejacket } \\
\hline Yes & $2(3)$ \\
\hline No & $68(97)$ \\
\hline \multicolumn{2}{|c|}{ Victim was under the influence of alcohol or drugs } \\
\hline Yes & $10(14)$ \\
\hline No/Do not know & $60(86)$ \\
\hline \multicolumn{2}{|l|}{ Type of boat involved ${ }^{\star} \dagger$} \\
\hline Small fishing boat & $56(84)$ \\
\hline Large fishing boat & $11(16)$ \\
\hline Passenger ferry & $0(0)$ \\
\hline \multicolumn{2}{|l|}{ Method of power of boat involved ${ }^{*}$} \\
\hline Engine & $24(36)$ \\
\hline Sails & $3(4)$ \\
\hline Paddles & $40(60)$ \\
\hline \multicolumn{2}{|l|}{ Boat was overcrowded or overloaded* } \\
\hline Yes & $3(4)$ \\
\hline No/Do not know & $64(96)$ \\
\hline \multicolumn{2}{|l|}{ Boat was inadequately maintained* } \\
\hline Yes & $10(15)$ \\
\hline No/Do not know & $57(85)$ \\
\hline
\end{tabular}

Data shown are $\mathrm{N}(\%)$.

*Data are shown for the 67 fishermen who were on a boat prior to the drowning incident.

†All boats were reportedly made from wood.

approximately 3-5 m) fishing boats. All boats involved were made of wood, and $41(57 \%)$ were powered by paddles only. Few boats were reportedly overloaded with people $(4 \%)$ or other items $(11 \%)$, and only $15 \%$ were considered poorly maintained. Seventy $(81 \%)$ of the 86 victims' bodies were recovered, and $9(10 \%)$ were taken to a health facility. Circumstances of drowning deaths specifically among fishermen are presented in table 3 . 


\section{Socioeconomic impact of drowning}

Twenty-two semi-structured interviews were conducted with family members $(n=10)$, colleagues ( $n=11$, all fishers) and a fellow community member $(n=1)$ of 26 persons who drowned (21 fishers, 3 children and 2 other community members) (figure 2). All interviewees were aged 24-58 years, and 13 (59\%) were men.

The most commonly raised socioeconomic impact on family members was loss of income and support (reported for 22/23 drowning cases among adults).

'I was thrown out of the house that we were renting so I had to look for a more affordable one... It has been an unending struggle with these children'. (Victim's wife)

'The family depended a lot on him, despite him not having children of his own... He was the breadwinner of the family'. (Victim's close friend)

Many described family breakdowns, having to find other sources of income, and moving away (reported for $15 / 26$ drowning cases).

'After he passed away the family separated. They closed the house and moved away'. (Victim's aunt)

Most relatives noted the increased burden of caring for their family with a reduced income (reported for 17/23 drowning cases among adults).

'I became the provider of two families because they said I am the one who caused his death by letting him go fishing'. (Victim's brother-in-law)

Of the 21 fishers who drowned, 19 were reported to be the main breadwinner for their families before they died.

Colleagues (all fishers) focused particularly on the loss of man-power, leading to reduced production and/ or increased burden on those remaining (reported for $13 / 21$ drowning cases among fishers). In some cases, this led to business closures.

'For 3 months I was not able to find a faithful man like him that I can leave my boat with'. (Victim's colleague)

'After he died the canoe was taken back to its owner, because once a canoe causes a death people are normally afraid of it, so the owner may be forced to sell it'. (Victim's colleague)

Some colleagues also noted psychological impacts (reported for 11/21 drowning cases among fishers).

'I am afraid every day. You become worried every time you remember how he died'. (Victim's colleague).

\section{DISCUSSION}

The estimated incidence of drowning (217/100 000 population) among fishing communities in Northwest Tanzania was 43-fold higher than the estimated annual drowning mortality rate for Tanzania as a whole. ${ }^{8}$ Incidence rates estimated in the recent systematic review by Sarrassat $e t a l^{8}$ equate to approximately 2748 drowning deaths per year in Tanzania. However, based on results from our study, the World Bank's estimated population of 3 million persons supported by the fishing industry around Lake Victoria, ${ }^{12}$ and an approximated $60 \%$ of the lakeside population residing in Tanzania (personal communication based on GPS-based analyses), we estimate that there are between 2100 and 7700 drowning deaths occurring per year in these Tanzanian lakeside fishing communities alone. This likely reflects a significantly higher risk of drowning among populations living and working in and around the great African lakes. Furthermore, the death rates from drowning in our study far exceeded those for other widely-recognised health threats in the region such as HIV/AIDS, malaria and tuberculosis (with national annual mortality rates of $\sim 154,44$ and 50/100 000 population, respectively), ${ }^{20}$ and other injury-related deaths such as those from road traffic accidents (8/100 000 population nationally). ${ }^{22}$

The majority of persons who drowned in our study were fishermen aged 18-40 years. Most fishermen had at least 1 year of experience in the industry but died while fishing at night, many in small wooden boats powered only by paddles. Fishing at night from comparatively small boats is a common practice in fishing communities in East Africa. At night time, lamps are used in Lake Victoria to attract small fish called dagaa (known as omena in Kenya and mukene in Uganda). Most deaths occurred because the boat sank or capsized in bad weather and rough water conditions. Anecdotal evidence suggests that many fishermen from these communities routinely fish in bad weather because they do not have an income if they do not fish. Stormy weather was also reported as a risk factor for drowning in the recent Ugandan study. ${ }^{10}$

Other factors associated with drowning among fishermen in our study included an inability to swim and not using life jackets. The inability to swim is common in these types of communities, where there is no infrastructure or expertise for swimming lessons. Further data from our study suggest that available life jackets are considered unaffordable (ranging from $\sim \mathrm{US} \$ 15$ to 150 ); the cheapest (non-ISO-conforming buoyancy vests) are seen by fishers as uncomfortable and ineffective (data not shown). A recent systematic review reported comfort, accessibility and ownership, and confidence in life jackets as key factors related to life jacket use. ${ }^{23}$ Male gender and adult age were associated with non-use of life jackets. It should, however, be noted that none of the studies included in the review were from LMICs. Overcrowding or overloading of boats was uncommon in the opinion of our study participants. Although Kobusingye et al did report overloading as a risk factor, a large proportion of victims in the Ugandan study died during transportation, ${ }^{10}$ which was not the case in our study.

All child victims identified by our study were under the age of 10 , consistent with other studies of fatal drowning 
among children. ${ }^{2} 45811$ Most drowned while swimming or playing at the lakeshore without permission or adult supervision. Many children did not routinely go in or near the water, but most of these had nonetheless gone in the water on purpose when they drowned. Of those who went in water regularly, swimming or playing in the lake without permission and unsupervised was common practice. Other factors associated with drowning among children included the inability to swim and not using life jackets. Although a lack of barriers around the water was also commonly reported, this may not be realistic in this setting.

Major floods took place in Tanzania in February and April 2016, ${ }^{24} 25$ and in October 2017. ${ }^{26}$ Although these mostly affected other parts of the country, including Morogoro, Katavi and Dar es Salaam, almost $13 \%$ of the drowning deaths identified in the lake-zone region in our study (among 10 fishermen and 1 child) occurred during one of the affected months (April 2016). Thus, the high number of deaths during this month may have been at least in part attributable to the bad weather and flooding. The numbers of identified drowning deaths occurring during the other affected months were not higher than during unaffected months.

Persons identified in our study who drowned were mainly from the economically productive age group, and their death had broad societal implications. Impacts of drowning on their families were varied and substantial, ranging from loss of homes and income to family breakdown. Where the person who drowned was a fisherman, he was often the main breadwinner for his family. Among colleagues of the persons who drowned, reported impacts included loss of man-power and income, and pressure to provide money or other support to the family of the person who drowned.

To our knowledge, this is the only study conducted outside South Africa that provides a robust estimation of drowning incidence and matched data on victims' demographics and behaviours and circumstances of drowning incidents for a sizeable yet neglected at-risk population in Sub-Saharan Africa. The communities were closeknit and data collection continued until saturation. We therefore believe we identified most or all drowning deaths occurring over the study period. Nonetheless, under-reporting is possible due to the lack of available comprehensive death records. In settings with larger, less close-knit communities without such a well-defined hierarchical structure, our networking approach would be less feasible; an alternative approach would be to conduct a household survey.

Our primary incidence analyses were conducted using 2012 census data with a $3 \%$ annual population growth applied to obtain 2016 population estimates as the population-at-risk. We considered census data to be the most reliable population data available at the community level, and multiple published records show that population growth in Tanzania has been stable at $\sim 3 \%$ for $\sim 15$ years. ${ }^{16-18}$ However, there are known limitations of using census data in applications such as this due to the time elapsed and population mobility. ${ }^{27}$ We thus performed sensitivity analyses using community-derived population estimates. For two communities, these differed significantly from our census-derived estimates, possibly reflecting high levels of migration. Nonetheless, the sensitivity analyses did not principally alter our findings. Where possible, we also validated population estimates using a previously published method combining data on the satellite-derived area of a given community with the average population density for lakeside fishing communities. ${ }^{28}$ Pooled satellite image-based population estimates were within $6 \%$ of census-derived estimates, and $0.5 \%$ of community-derived estimates (data not shown). To ensure that all identified drowning cases were derived from the denominator population, we excluded reports of persons not permanently or temporarily resident in the targeted communities at the time they drowned, but it should be noted that these populations are typically highly mobile.

A key strength of our study was the careful comparison of descriptions of each drowning victim and incident, enabling the removal of duplicated reports. This may explain the lower drowning rates in our study than in the Ugandan study (502/100 000 population), ${ }^{10}$ where descriptive data of victims and drowning deaths were not collected and compared, potentially resulting in over-reporting. However, there were also differences in target populations, with the Ugandan study targeting boat landing sites rather than fishing communities. Given that our results are derived from eight sizeable island and mainland fishing communities from four districts around the Tanzanian shoreline of Lake Victoria, our results are likely to be generalisable to other similar communities situated around large lakes in East Africa, and possibly Sub-Saharan Africa more generally.

A limitation of our study is that the cause of death was rarely confirmed by a post-mortem. This is typical of this setting, where the deceased are seldom taken to hospitals, and facilities enabling post-mortem are limited. In $90 \%$ of cases, we were able to collect sufficiently detailed information on the circumstances of the incident and eyewitness accounts to conclude that drowning was the most likely cause of death. Contribution of medical (eg, cardiac) conditions cannot be ruled out, though this was probably uncommon given the age range of most persons who drowned. All but one of the remaining victims were taken to a health facility, where the cause of death was deemed to be drowning. In most cases, the availability of witnesses allows us to confirm with reasonable certainty that the death was unintentional. However, where witnesses were not present, intentional drowning cannot be ruled out.

The infrequency of persons from these rural communities who drowned being taken to health facilities may explain, in part, the failure to identify a higher drowning risk among fishermen in the recent systematic review by Sarrassat $e t$ al, which derived a significant proportion of included data from hospital-based sources. ${ }^{8}$ However, other limitations surrounding data availability for the 
review may also contribute to the disparity in findings. Some sources reported drowning data only from larger scale disasters or from boating incidences involving large vessels; and many household surveys or surveillancebased studies reported data at a regional level and did not hone down to specific sub-populations such as individual fishing communities. ${ }^{8}$ A paucity of available drowning mortality data in Tanzania was recognised as a limitation by the authors of the systematic review.

To maximise accuracy in descriptive data on risk factors, we only studied drowning deaths occurring in the preceding 2 years and purposely selected participants who were most likely to know the characteristics of the persons who drowned and circumstances of their deaths for the questionnaires. Nonetheless, the nature of the study, whereby participants retrospectively answered questions about the persons who drowned, means that recall bias could be present. Furthermore, some of the risk factors, such as fishing from poorly maintained boats, were subjective as we did not have the means to define or validate responses. Our qualitative data on the perceived impacts of drowning represent an interesting but preliminary assessment. In many cases, family members and colleagues of persons who drowned were not living in the community, so data were limited. A detailed quantitative economic evaluation was outside the remit of this study.

This study highlights that drowning is a significant health threat among Tanzanian (and possibly other East-African) fishing communities on Lake Victoria, with fishermen most affected. Yet risk-taking behaviours were commonly reported, and preventative tools such as life jackets were hardly used. Averting drowning in these communities should be considered a public health priority, and authorities need to engage in intervention strategies such as tighter enforcement of adequate boat maintenance standards and safe boating practices. Data from similar populations living and working on large water bodies worldwide will help to quantify the public health burden of unsafe water practices, particularly in low-income settings.

\section{Author affiliations}

${ }^{1}$ Mwanza Intervention Trials Unit, Mwanza, Tanzania

${ }^{2}$ Department of Clinical Research, London School of Hygiene and Tropical Medicine, London, UK

${ }^{3}$ Uganda Virus Research Institute, Entebbe, Uganda

${ }^{4}$ Department of Infectious Disease Epidemiology, London School of Hygiene and Tropical Medicine, London, UK

${ }^{5}$ Department of Global Health and Development, London School of Hygiene and Tropical Medicine, London, UK

Acknowledgements The authors are very grateful to the fishermen and other fishing community members who participated in the study, as well BMU/community leaders and local authorities who facilitated the research at each study site. They also thank the following Research Assistants and Data Managers who contributed to data collection and management: Francis Kapinga, Abdul Mashauri, Ramadhan Hashim and Ezekial Mjema. Finally, they are grateful to Ronnie Kasirye for his contribution to the application for study funding, and Elialilia Pallangyo for her advice and support in qualitative analyses and interpretation.

Contributors HSW, CH and HG: conceptualised the study. HSW and CH: wrote the study protocol. HSW provided study oversight, with support from $\mathrm{CH}, \mathrm{DW}-\mathrm{J}$,
SK and HG. JP: responsible for day-to-day study coordination and management of field staff. JP also conducted data collection together with research assistants $\mathrm{AM}, \mathrm{HM}, \mathrm{OR}$ and MJ. $\mathrm{CH}$ : led analyses of drowning incidence estimations, and HSW and PA produced data tables for all other quantitative data. NH and AM: conducted qualitative analyses and interpretation. HSW: drafted the manuscript, with contributions from all authors. All authors had full access to all study data and reviewed and agreed on the version of the manuscript for submission.

Funding This study was funded by Royal National Lifeboat Institution.

Map disclaimer The depiction of boundaries on the map(s) in this article do not imply the expression of any opinion whatsoever on the part of BMJ (or any member of its group) concerning the legal status of any country, territory, jurisdiction or area or of its authorities. The map(s) are provided without any warranty of any kind, either express or implied.

Competing interests The Royal National Lifeboat Institution (RNLI) provided study funding but played no role in the study design, data collection, analysis and interpretation, or manuscript writing. For the duration of the study, funding from the RNLI contributed partial salary costs for HSW and NH, and full salary costs for JP, $\mathrm{OR}, \mathrm{AM}, \mathrm{HM}$ and MJ. HSW, SK, CH, PA, NH, DW-J and HG receive funding support from LSHTM.

Patient consent for publication Not required.

Provenance and peer review Not commissioned; externally peer reviewed.

Data availability statement Data are available upon reasonable request.

Open access This is an open access article distributed in accordance with the Creative Commons Attribution Non Commercial (CC BY-NC 4.0) license, which permits others to distribute, remix, adapt, build upon this work non-commercially, and license their derivative works on different terms, provided the original work is properly cited, appropriate credit is given, any changes made indicated, and the use is non-commercial. See: http://creativecommons.org/licenses/by-nc/4.0/.

ORCID iD

Hilary S Whitworth http://orcid.org/0000-0003-2353-2352

\section{REFERENCES}

1. World Health Organization. Violence and injury prevention. drowning. Available: https://www.who.int/violence_injury_prevention/drowning/ en/ [Accessed 08 Aug 2019].

2. Tyler MD, Richards DB, Reske-Nielsen C, et al. The epidemiology of drowning in low- and middle-income countries: a systematic review. BMC Public Health 2017;17:413.

3. Saunders CJ, Adriaanse R, Simons A, et al. Fatal drowning in the Western Cape, South Africa: a 7-year retrospective, epidemiological study. Inj Prev 2018:injuryprev-2018-042945--2016.

4. Lin C-Y, Wang Y-F, Lu T-H, et al. Unintentional drowning mortality, by age and body of water: an analysis of 60 countries. Inj Prev 2015;21:e43-50.

5. Chasimpha S, McLean E, Chihana M, et al. Patterns and risk factors for deaths from external causes in rural Malawi over 10 years: a prospective population-based study. BMC Public Health 2015;15:1036.

6. Halawa EF, Barakat A, Rizk HII, et al. Epidemiology of non-fatal injuries among Egyptian children: a community-based crosssectional survey. BMC Public Health 2015;15:1248.

7. Weldearegawi $\mathrm{B}$, Ashebir $\mathrm{Y}$, Gebeye $\mathrm{E}$, et al. Emerging chronic noncommunicable diseases in rural communities of northern Ethiopia: evidence using population-based verbal autopsy method in Kilite Awlaelo surveillance site. Health Policy Plan 2013;28:891-8.

8. Sarrassat S, Mrema S, Tani K, et al. Estimating drowning mortality in Tanzania: A systematic review and meta-analysis of existing data sources

9. Kobusingye O, Guwatudde D, Lett R. Injury patterns in rural and urban Uganda. Inj Prev 2001;7:46-50.

10. Kobusingye $\mathrm{O}$, Tumwesigye NM, Magoola J, et al. Drowning among the lakeside fishing communities in Uganda: results of a community survey. Int J Inj Contr Saf Promot 2017;24:363-70.

11. World Health Organization. Global report on drowning: preventing a leading killer; 2014.

12. World Bank. Lake Victoria environmental management project (LVEMP) APL-1; 2015.

13. Thiery W, Davin EL, Seneviratne SI, et al. Hazardous thunderstorm intensification over lake Victoria. Nat Commun 2016;7:12786.

14. Asiki G, Mpendo J, Abaasa A, et al. Hiv and syphilis prevalence and associated risk factors among fishing communities of Lake Victoria, Uganda. Sex Transm Infect 2011;87:511-5. 
15. Whitworth $\mathrm{H}$. An observational study to inform potential drowning intervention strategies among fishing communities in the lake zone of Tanzania (DRIFT). London, United Kingdom London School of Hygiene \& Tropical Medicine; 2018.

16. City population: Tanzania. Available: http://www.citypopulation.de/ php/tanzania-lake-admin.php [Accessed 05 Dec 2018].

17. Agwanda A, Amani H. Population growth, structure and momentum in Tanzania. The Economic and Social Research Foundation; 2014.

18. The World Bank. Population growth (annual \%), 2018. Available: https://data. worldbank.org/indicator/SP.POP.GROW?locations=TZ\& year_high_desc=true [Accessed 05 Dec 2018].

19. Clarke V, Braun V. Successful qualitative research: a practical guide for beginners. London: Sage, 2013.

20. World Health Organisation. United Republic of Tanzania: who statistical profile. Available: http://www.who.int/gho/countries/tza. pdf?ua=1 [Accessed 05 Dec 2018].

21. World Health Organization. Global tuberculosis report 2017, 2017. Available: http://www.who.int/tb/publications/global_report/ gtbr2017_main_text.pdf [Accessed 12 Apr 2018].

22. World Health Organisation. United Republic of Tanzania, 2013. Available: http://www.who.int/violence_injury_prevention/road_ safety_status/2013/country_profiles/united_republic_of_tanzania. pdf?ua $=1$ [Accessed 12 Apr 2018].

23. Peden AE, Demant D, Hagger MS, et al. Personal, social, and environmental factors associated with lifejacket wear in adults and children: a systematic literature review. PLoS One 2018;13:e0196421.

24. Ngaina J. Tanzania - floods in 3 regions, 6 people dead, more rain forecast. FloodList, 2016. Available: http://floodlist.com/africa/floodsjanuary-february-2016-tanzania [Accessed 16 Aug 2019].

25. Juma B. Tanzania - 3 dead, 100 s displaced after floods in Mbeya, Zanzibar and Kilimanjaro regions. FloodList, 2016. Available: http:// floodlist.com/africa/tanzania-floods-mbeya-zanzibar-kilimanjaro [Accessed 16 Aug 2019].

26. Fox E. Torrential downpours cause major flooding in Tanzania, 2017. Available: https://www.aljazeera.com/news/2017/10/torrentialdownpours-major-flooding-tanzania-171027094535520.html [Accessed 16 Aug 2019].

27. Sim F, McKee M. Issues in public health. London: McGraw-Hill Education, 2011.

28. Nash S, Tittle V, Abaasa A, et al. The validity of an area-based method to estimate the size of hard-to-reach populations using satellite images: the example of fishing populations of Lake Victoria. Emerg Themes Epidemiol 2018;15:11. 